\title{
Short-term memories in Drosophila are governed by general and specific genetic systems
}

\author{
Troy Zars $^{1}$ \\ Division of Biological Sciences, University of Missouri, Columbia, Missouri 65211, USA
}

\begin{abstract}
In a dynamic environment, there is an adaptive value in the ability of animals to acquire and express memories. That both simple and complex animals can learn is therefore not surprising. How animals have solved this problem genetically and anatomically probably lies somewhere in a range between a single molecular/anatomical mechanism that applies to all situations and a specialized mechanism for each learning situation. With an intermediate level of nervous system complexity, the fruit fly Drosophila has both general and specific resources to support different short-term memories. Some biochemical/cellular mechanisms are common between learning situations, indicating that flies do not have a dedicated system for each learning context. The opposite possible extreme does not apply to Drosophila either. Specialization in some biochemical and anatomical terms suggests that there is not a single learning mechanism that applies to all conditions. The distributed basis of learning in Drosophila implies that these systems were independently selected.
\end{abstract}

In a dynamic environment, there is adaptive value in the ability to learn from experience and use memories to make predictions about future good or bad events. Thus, it is not surprising that the ability to learn evolved early and is found in diverse organisms, from relatively simple animals like C. elegans and Aplysia, to insects, and mammals. Learning mechanisms can in principle lie between two extremes-either a single mechanism that is applied to all situations, or a unique mechanism for each learning context. Learning mechanisms here indicates the molecular and anatomical structures, or the system, that supports formation of a memory. It is now clear that Drosophila, an animal with an intermediate level of nervous system complexity, solves learning problems with an intermediate system. That is, flies have multiple overlapping molecular and anatomical structures that are critical for memory formation in different conditions. Thus, as an example, although the mushroom bodies in the fly brain are important for some forms of learning, other brain structures are important in several different learning contexts. Specificity of memory formation systems in different learning situations is further supported by investigations into the biogenic amines and the isolation of several mutations that alter learning. Although a model for how the Drosophila brain supports learning is far from complete, results from the last decade have rejected the notion of a single learning mechanism in Drosophila.

Three types of learning in Drosophila will be discussed with respect to anatomical and genetic organization. These include classical olfactory conditioning, operant place conditioning, and operant and classical visual conditioning. The behavioral tests will be only briefly described here as they have been recently well reviewed elsewhere (Davis 2005; Keene and Waddell 2007; Heisenberg and Gerber 2008).

\section{Behavioral paradigms for testing short-term memory}

Classical olfactory conditioning typically associates one of two odorants with a negative or positive "unconditioned stimulus"

\footnotetext{
'Corresponding author.
}

E-mail zarst@missouri.edu; fax (573) 884-5020.

Article is online at http://www.learnmem.org/cgi/doi/10.1101//m.1706110.
(US). Because the odorants and USs are presented to flies in a way that is independent of any behavior a fly might be performing, it is considered classical conditioning (Pavlov 1927). After conditioning, when flies are allowed to choose between the two odorants, the majority of animals usually move away from the odorant previously associated with an aversive US, or toward the odorant previously associated with an appetitive US (Davis 2005; Keene and Waddell 2007; Heisenberg and Gerber 2008; Zars 2010). A classically conditioned olfactory memory has been identified in both the larval and adult life stage of Drosophila. In the simplest test of larval olfactory memory, larvae choose between the two odorants on a Petri plate within a few minutes of training (Scherer et al. 2003; Gerber et al. 2009). In the adult fly, typically groups of flies are presented with the two odorants at a T-maze choice point (Fig. 1; Tully and Quinn 1985). Short-term memory with a few odorant/US pairings is tested from minutes to hours after training (Tully and Quinn 1985; Tully et al. 1994). An interesting twist to the odorant/shock protocol involves altering the timing of shock and odorant presentation. Shock presentation that shortly precedes odorant presentation actually leads to flies approaching that odorant (Tanimoto et al. 2004; Yarali et al. 2009). Finally, a recently developed paradigm also allows for mixed operant (defined below)/ classical conditioning of odorants. This mixed conditioning seems to be more effective than strict classical conditioning (Claridge-Chang et al. 2009). Successful completion of these tasks depends on effective memory recall and appropriate orientation and taxis behaviors (that is avoidance of an area filled with the odorant previously associated with electric shock, or toward the odorant previously associated with sugar reward).

Operant place conditioning uses the heat-box (Wustmann et al. 1996; Zars 2009). In individual long but narrow chambers, single flies are allowed to roam, and they usually walk from chamber end to chamber end (Zars et al. 2000b). During training, one half of the chamber can be associated with rising temperatures (acting as a negative reinforcer) (Fig. 1). Flies typically avoid the chamber half associated with these high temperatures, and continue to do so even after the chamber temperature is reset to the preferred $24^{\circ} \mathrm{C}$ (Wustmann and Heisenberg 1997; Zars et al. 2000b; Zars and Zars 2006). This paradigm is considered an 
A

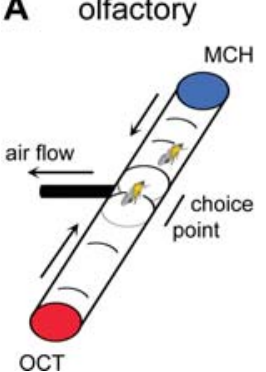

B visual pattern

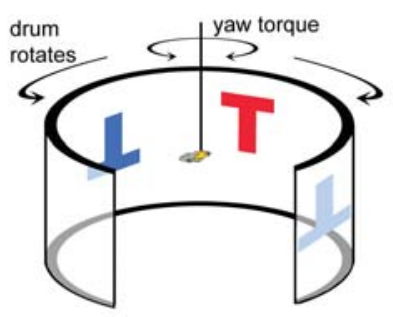

C

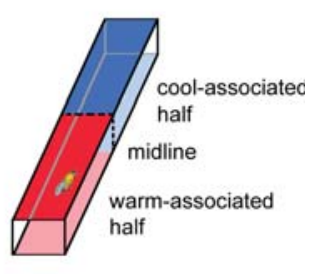

Figure 1. Schematics of three learning paradigms. $(A)$ Olfactory learning typically associates electric shock or sugar with one of two odorants (methylcyclohexanol [MCH] and octanol [OCT] represented here) (Tully and Quinn 1985). Flies are allowed to choose between the two odorants as air flow moves the odorants over the flies simultaneously at the choice point. $(B)$ Visual pattern learning associates different visual pattern parameters with high temperature. In this case, the elevation of the center of gravity (upright T) is associated with high temperatures (Dill et al. 1993). Yaw torque generated by the fly controls drum rotation, bringing the inverted $T$ in front of a single fly. (C) Place learning associates one end of a narrow chamber with warm temperatures, the other half of the chamber with cool temperatures (Wustmann et al. 1996). When a fly crosses the midline, the whole chamber warms or cools. Represented here is a fly running out of the warm-associated chamber half.

operant task (Skinner 1950) because the rising temperature negative reinforcement depends on a fly performing some behavior (e.g., walking to the back of the chamber). It may, however, be a task that has both operant and classical components, associating both the behavior (operant) and a place (classical) in the chamber with rising temperatures. Place memory is typically tested directly after training, but can also be measured after hours of rest in a vial if the flies are provided with a short reminder training (Putz and Heisenberg 2002). Again, as in classical olfactory conditioning, successful completion of the test requires a memory and the ability to orient and walk toward a preferred location.

The flight simulator has been used to examine visual pattern memories after mixed operant and classical conditioning, or separate operant or classical conditioning (Brembs and Heisenberg 2000; Heisenberg et al. 2001; Brembs and Plendl 2008). In all cases, flies are fixed in space by a hook on the thorax connected to a torque compensator. This compensator provides feedback to the fly by changing visual patterns on the walls of a surrounding arena in proportion to the intended changes in orientation through torque generation to the fly's left or right (Fig. 1). In the mixed conditioning paradigm, high temperature is paired with the behavior that brings one of two visual patterns (or colors) to the front of the visual field. In operant conditioning, the yaw torque left or right can be associated with high temperature. In classical conditioning alone, the patterns and associated high temperatures are presented to the fly independent of yaw torque behavior. Memories, through modified preference for visual patterns or behaviors, can be measured hours later (Xia et al. 1997; Heisenberg et al. 2001). The task here depends both on a memory and the ability to orient in the flight simulator.

\section{Neural circuitry implicated in short-term memory}

\section{Mushroom bodies}

The mushroom bodies are a paired structure of $\sim 2500$ Kenyon cell neurons that cross nearly the entire anterior/posterior dimensions of the central brain (Fig. 2). They are part of the olfactory pathway in Drosophila and other insects. The Kenyon cell dendrites are in the calyces, and are at the second synapse level in the olfactory pathway (Heisenberg 2003; Gerber et al. 2009). The Kenyon cell axons form the mushroom body lobes, projecting medially and vertically in the anterior brain. Within the lobes there is a further refined organization into the $\alpha / \beta, \alpha^{\prime} / \beta^{\prime}$, and $\gamma$ experimentally altered by genetic mutation, chemical ablation, and transgenic manipulation. In a screen for mutations that alter the structure of the fly brain, the genes mushroom body miniature $(\mathrm{mbm})$ and mushroom body deranged $(\mathrm{mbd})$ were found to alter the gross structure of the mushroom bodies (Heisenberg et al. 1985). Furthermore, selective ablation of the mushroom bodies can be accomplished by feeding the drug hydroxyurea (HU) to early first instar larvae (de Belle and Heisenberg 1994). Finally, the properties of the mushroom bodies can be altered by expressing different transgenes in the Kenyon cells with the GAL4/UAS system and a small set of GAL4 drivers (Brand et al. 1994; Heisenberg and Gerber 2008). In this latter approach G-protein signaling, rutabaga adenylyl cyclase (rut-AC), amnesiac function (in mushroom body extrinsic neurons), and shibire dynamin-dependent synaptic transmission have been manipulated.

Manipulation of the mushroom bodies indicates that they are important for several, but not all, learned behaviors. Olfactory memories depend on the function of the mushroom bodies. Using the $\mathrm{mbm}$ and $m b d$ mutations and HU feeding the mushroom bodies were shown to be necessary for classically conditioned olfactory memories (Heisenberg et al. 1985; de Belle and Heisenberg 1994). Our understanding of the importance of the mushroom bodies in olfactory memory was extended by manipulation of G-protein, rut-AC, and amnesiac signaling, and shibiredependent processes in the Kenyon cells and the so-called DPM mushroom body extrinsic neurons (Connolly et al. 1996; Waddell et al. 2000; Zars et al. 2000a; Dubnau et al. 2001; McGuire et al. 2001, 2003; Schwaerzel et al. 2002; Mao et al. 2004; Ferris et al. 2006).

The different lobes of the mushroom bodies have been implicated in various components of aversive olfactory memory. The $\alpha / \beta, \alpha^{\prime} / \beta^{\prime}$, and $\gamma$ lobes can be addressed with different sets of GAL4 drivers and with a genetic mutation that alters the $\alpha / \beta$, $\alpha^{\prime} / \beta^{\prime}$ lobes. The $\alpha / \beta$ and $\gamma$ lobes have been implicated in rut-AC-dependent short-term memory formation, and regulated cAMP signaling may be involved in different temporal phases within these lobes (Zars et al. 2000a; McGuire et al. 2003; Mao et al. 2004; Blum et al. 2009). Furthermore, an $\alpha^{\prime} / \beta^{\prime}$ lobe function has been identified for olfactory memory consolidation (Krashes et al. 2007). The mutation alpha-lobes-absent (ala), sometimes removes the $\alpha$ and $\alpha^{\prime}$ lobes, sometimes the $\beta$ and $\beta^{\prime}$ lobes. When ala mutant flies lack the $\alpha$ and $\alpha^{\prime}$ lobes, olfactory long-term memory is abolished (Pascual and Preat 2001). Remarkably, 
A

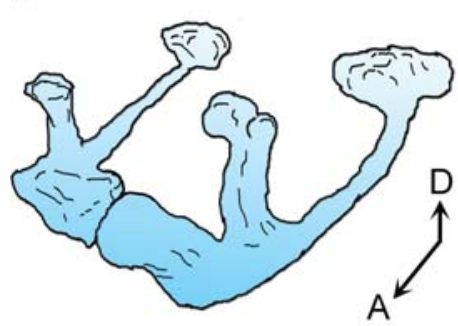

C

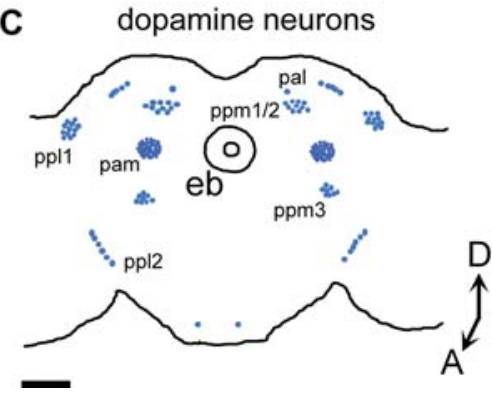

B fan-shaped body

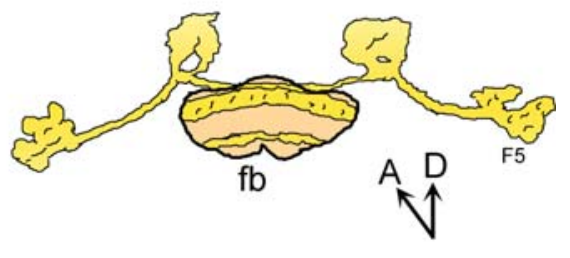

D

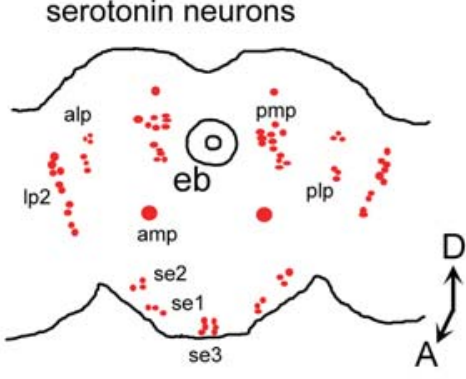

Figure 2. Parts of the nervous system that are differentially required for learning in different contexts are shown. (A) The mushroom bodies (MB), a paired structure in the central brain (Zars 2000), are important for olfactory learning, but not visual pattern recognition memory or place memory. $(B)$ F5 neurons, which innervate specific layers of the fan-shaped body (FB), are critical for visual pattern recognition memory (Liu et al. 2006). (C) The location of the dopaminergic cell bodies in the central brain (Friggi-Grelin et al. 2003). These neurons are important for aversive olfactory memories, but not straight-forward appetitive olfactory memories or place learning. $(D)$ The serotonergic neurons in contrast (location of cell bodies are shown) are important for place learning (Sitaraman et al. 2008). The scale bar represents $50 \mu \mathrm{m}$ in $A$ and $B, 100 \mu \mathrm{m}$ in $C$ and $D$.

visualization of cAMP and PKA activity in the mushroom bodies with paired application of acetylcholine and dopamine or octopamine (discussed below) leads to synergistic increases in these signals in different lobe patterns (Tomchik and Davis 2009; Gervasi et al. 2010). With acetylcholine/dopamine presentation, the $\alpha$ lobes show an increase in PKA activity; acetylcholine/octopamine presentation leads to increases of PKA activity in the $\alpha, \beta$, and $\gamma$ lobes.

A model has emerged in which the connection between Kenyon cells and mushroom body extrinsic neurons is altered during training (via a coincident excitation of these neurons with US and odorant presentation) in such a way as to alter cAMP/PKA signaling and, thus, a fly's preference for an odorant in the T-maze test (Waddell et al. 2000; Zars et al. 2000a; Heisenberg 2003; Gerber et al. 2004; Tomchik and Davis 2009; Gervasi et al. 2010). The change in odorant preference depends on the altered connection between the Kenyon cells and postsynaptic mushroom body extrinsic neurons.

The mushroom bodies do not have a function in straightforward place memory in the heat-box or visual pattern memory in the flight simulator. HU ablation or alteration of mushroom body structure as a result of $\mathrm{mbm}$ or $\mathrm{mbd}$ mutation does not alter conditioned behavior or place memory (Wolf et al. 1998; Putz and Heisenberg 2002). Furthermore, using the same tools, visual pattern memory appears intact in flies without mushroom bodies (Liu et al. 1999). Alteration of the mushroom bodies, however, reveals their function in more complicated memory functions in the flight simulator. Manipulation of the mushroom bodies inhibits the ability of flies to generalize memory performance across visual contexts (color or presence of intermittent lighting) and destroys the typical coherent shift in preference for colors or patterns in conflicting memory test conditions (Liu et al. 1999; Tang and Guo 2001). Furthermore, by expressing the tetanus

\begin{abstract}
important for recognition of different
\end{abstract} pattern parameters (i.e., relative elevation of the center of gravity and edge orientation).

A conceptual model for pattern recognition in Drosophila has been proposed (Tang et al. 2004). Peripheral feature detectors provide afferent information to the central brain with both what and where information (channels). Selective visual attention as an efferent where component and an efferent what component provide the final two channels in the model. With conditioning, when a high temperature or other US is associated with a visual pattern, the afferent what channel can be used to switch the behavior of an efferent what channel for that visual feature. Whenever the now danger-predicting visual feature is detected in the peripheral feature detectors, regardless of where they are detected, that feature information is directly channeled to the central brain. Flies then initiate motor commands to avoid the danger-predicting visual feature. The visual memory trace in the central complex should provide a critical component of this pattern recognition model.

\section{Reinforcement mechanisms}

The biogenic amines provide a key role in memory reinforcement mechanisms in animals. In Drosophila, dopamine, octopamine, and serotonin have been found to play critical but different functions in reinforcement learning (Fig. 2; Schwaerzel et al. 2003; Schroll et al. 2006; Sitaraman et al. 2008; ClaridgeChang et al. 2009). The dopamine and octopamine neurons are thought to differentiate between aversive and appetitive olfactory memories, although this strict distinction has been recently challenged. A role for serotonin has been identified in place learning.

The dopamine neurons in Drosophila have a role in some aversive memories. The dopamine neurons innervate several 
regions of the nervous system, including the mushroom bodies (Mao and Davis 2009; Selcho et al. 2009). These neurons can be manipulated using several GAL4 and GAL80 (a repressor of GAL4 function) drivers. GAL4 drivers have been developed and used to manipulate the dopaminergic system or subsets of that system, either by cloning the regulatory regions of the tyrosine hydroxylase gene (to make TH-GAL4 and TH-GAL80) or screening of GAL4 insertion libraries (Friggi-Grelin et al. 2003; Schwaerzel et al. 2003; Sitaraman et al. 2008; Claridge-Chang et al. 2009; Krashes et al. 2009). Furthermore, pharmacological treatment (feeding flies alpha-methyl tyrosine) can be used to lower dopamine levels (Sitaraman et al. 2008). Using a temperature sensitive mutant of the shibire dynamin transgene expressed with the TH-GAL4 driver, it was found that the dopaminergic neurons are necessary for acquisition of an aversive olfactory memory in adult and larval Drosophila (Schwaerzel et al. 2003; Selcho et al. 2009). Moreover, activation of the dopaminergic neurons using light induced opening of the Channel-Rhodopsin 2 (ChR2) cation channel, or the local activation of a purine receptor channel in these neurons, paired with exposure to an odorant, led to a memory in which larvae and adult flies avoided that odorant (Schroll et al. 2006; Claridge-Chang et al. 2009). Blocking of TH-positive neurons with temperature sensitive shibire dynamin did not alter appetitive olfactory memory in adult flies (Schwaerzel et al. 2003). Interestingly, however, altering the function of TH-positive neurons and mutation of the dumb dopamine receptor, both affect appetitive olfactory learning in larvae (Selcho et al. 2009). Furthermore, the gating of appetitive olfactory memory in adult flies based on the sated state requires the function of some of the dopaminergic neurons (Krashes et al. 2009). The dopaminergic system is not important for place memory (Sitaraman et al. 2008). Whether the dopaminergic system is important for visual learning has not been reported. Thus, the dopaminergic neurons have a critical function in aversive olfactory learning in larval and adult flies, gating of appetitive olfactory learning in adult flies, and appetitive olfactory learning in larvae.

Octopamine is important in appetitive olfactory learning. Mutation of the T $\beta \mathrm{H}$ gene lowers octopamine and elevates tyramine levels. Mutant T $\beta H$ flies have impaired appetitive olfactory memory, but aversive olfactory memory is unaffected (Schwaerzel et al. 2003). Furthermore, using the ChR2 protein in octopaminergic neurons with a TDC-GAL4 driver, and pairing the activation of the octopaminergic neurons with odorant exposure induces the acquisition of an appetitive olfactory memory in Drosophila larvae (Schroll et al. 2006). Although one might predict that in place conditioning, a falling temperature associated with part of the heat-box chamber could be rewarding, $\mathrm{T} \beta \mathrm{H}$ and blockade of TDC-positive neurons with the TeTxLC does not influence place memory (Sitaraman and Zars 2010). Octopamine is critical for flight initiation (Brembs et al. 2007), making it difficult at the moment to study the role of octopamine in visual pattern memory formation.

Serotonin is another biogenic amine that is important in modulating several behaviors (Fig. 2). Because tools to manipulate the serotonergic system have only recently been developed, less is known about the role of serotonin in influencing memory formation. Using three means of altering the serotonergic system, it was concluded that serotonin is critical for matching the reinforcement intensity to place memory performance level (Sitaraman et al. 2008). In all cases, poor place memory levels were correlated with genetically or pharmacologically lowered serotonin levels or serotonin release. The function of the serotonergic system in appetitive and aversive olfactory memory is under investigation (H LaFerriere, D Sitaraman, and T Zars, unpubl.). The role of serotonin in visual pattern recognition memory has not been reported.

\section{Different genetic requirements for several forms of learning}

In addition to the genes and learning functions outlined above, for which neural system-specific functions have been determined, there are several additional genes that are differentially necessary for learning in various contexts (and there is patchy information on where these genes function in the nervous system to support short-term memory). These genes probably alter the physiology of neurons responsible for encoding different memories or the development of those systems. However, the observation that these genes sometimes have specific memory functions argues further for a unique genetic architecture that supports specific forms of memory.

The cAMP/PKA pathway and underlying neuronal plasticity function seems to be a general feature of memory formation. Mutation of either the type- 1 adenylyl cyclase (rut-AC), the cAMP phosphodiesterase $(d n c)$, or the DCO PKA regulatory subunit leads to altered memory formation in aversive and appetitive olfactory memory (McGuire et al. 2005). Place learning experiments have found that rut and $d n c$ are critical for normal memory formation (Wustmann et al. 1996; Zars et al. 2000b; Diegelmann et al. 2006; Zars 2009), although the DC0 PKA mutation has not been tested in this context. The amnesiac gene product also seems to have a common role in at least two learning contexts: olfactory and place learning (Feany and Quinn 1995; Waddell et al. 2000; Putz 2002). In the flight simulator, the rut-AC gene has been shown to be important for a component of the visual pattern memory (Brembs and Plendl 2008).

There are several other protein kinases that have been examined to various extents in olfactory, place, and visual pattern recognition memory. In all cases these kinases have differential effects on memory formation. These include PKC, PKG, and an S6K2. A protein kinase $\mathrm{C}$ (PKC) has been shown to be important in visual pattern memory (Brembs and Plendl 2008), and a modified PKC (PKM) was shown to enhance aversive olfactory memory formation (Drier et al. 2002). The function of this protein has not yet been tested in place learning. The foraging gene encodes a cGMP-dependent protein kinase (PKG) (Osborne et al. 1997). This gene was originally identified as one in which two natural alleles, foraging ${ }^{\text {Rover }}$ and foraging ${ }^{\text {sitter }}$, with relatively high and low PKG activities, respectively, resulted in two different feeding strategies. Variation at the foraging gene has been found to also be important for some forms of learning. Using a novel classical olfactory conditioning protocol (using mechanical shaking as the US), it was recently shown that the foraging ${ }^{\text {Rover }}$ flies had higher short-term memory than the foraging sitter flies (Mery et al. 2007). Olfactory learning in larvae was similarly affected by these alleles (Kaun et al. 2007). Furthermore, foraging ${ }^{\text {Rover }}$ flies performed better than foraging ${ }^{\text {sitter }}$ flies in visual pattern memory (Wang et al. 2008). In both of the olfactory cases, the $\sim 10 \%$ lower PKG activity of foraging sitter flies could be compensated with expression of the foraging cDNA in the mushroom bodies to restore higher memory levels. In visual pattern memories, increasing expression of the foraging PKG in parts of the central complex rescued memory defects of foraging sitter flies. In contrast to olfactory and pattern recognition, the differences between foraging ${ }^{\text {Rover }}$ and foraging ${ }^{\text {sitter }}$ alleles on PKG activity did not alter place learning (Gioia and Zars 2009). Thus, testing the same foraging alleles, classical olfactory learning, visual pattern recognition memory, and place learning, are differentially effected. Finally, S6K2 was identified in a screen for mutations that alter place learning (Putz et al. 2004). The first alleles identified were semi-dominant. Generation of loss-of-function alleles led to reduced olfactory short-term memory that could be rescued with expression of a transgenic genomic copy of the gene (Putz et al. 2004). Importantly, the loss of 
function alleles had no effect on place memory, and the semidominant alleles had no effect on olfactory learning. Thus, different alleles within the same gene altered different types of memory to various extents. Perhaps related to the place memory phenotype, a seconds-long orientation memory also depends on the S6K2 product (Neuser et al. 2008), which may indicate a relationship between orientation memory and place learning (Neuser et al. 2008; Zars 2009). An effect of the S6K2 gene has not been reported in visual pattern recognition memory.

Another approach to identifying genes that are important for learning is to examine mutant lines that are unusually sensitive to the behavioral effects of ethanol exposure. Earlier evidence suggested a common mechanism between ethanol responses (i.e., a rapid but short-lived increase in motor activity with ethanol exposure followed by loss of motor control) and learning based on cAMP and Fas2 functions (Moore et al. 1998; Cheng et al. 2001). Based on two different genetic screens, the relationship between these two behaviors was recently re-examined (Berger et al. 2008; Laferriere et al. 2008). Although it appears that there is a common set of genes important for ethanol response behavior and learning, there is no overall correlation between the two processes. Nevertheless, in terms of short-term memory, a new gene with interesting effects on olfactory memory and place learning has been identified. Mutation in the tribbles kinase leads to reduced place memory levels but higher than expected aversive olfactory memory levels (Laferriere et al. 2008). The tribbles kinase has not been investigated in visual pattern recognition memory.

\section{Conclusion}

Investigations of Drosophila reveal several mechanisms of memory formation. Visual pattern recognition, olfactory memory, and place learning are three sensory/behavioral domains in which flies readily alter behavior based on experience in the minutes to hours range. The differential requirement of the mushroom bodies, specialization of the reinforcement circuitry, and selective influence of some kinases on these forms of learning suggests that Drosophila has both common and specific memory formation mechanisms. Perhaps even more complicated is that there are multiple genetic solutions that can be selected in the laboratory to increase learning ability (Mery and Kawecki 2002; Kawecki and Mery 2006). The pattern of results from genetic intervention studies suggests that the mechanisms that support memory formation have been selected multiple times.

\section{Acknowledgements}

I offer thanks to Liz Kramer, Holly LaFerriere, Alex Sable-Smith, Divya Sitaraman, and Dr. Steve Alexander for providing critical comments on an early version of this manuscript. This work was supported by grants from the National Science Foundation (IOS 0613708) and the University of Missouri Research Board.

\section{References}

Berger KH, Kong EC, Dubnau J, Tully T, Moore MS, Heberlein U. 2008. Ethanol sensitivity and tolerance in long-term memory mutants of Drosophila melanogaster. Alcohol Clin Exp Res 32: 895-908.

Blum AL, Li W, Cressy M, Dubnau J. 2009. Short- and long-term memory in Drosophila require cAMP signaling in distinct neuron types. Curr Biol 19: $1341-1350$.

Brand AH, Manoukian AS, Perrimon N. 1994. Ectopic expression in Drosophila. Methods Cell Biol 44: 635-654.

Brembs B. 2009. Mushroom bodies regulate habit formation in Drosophila. Curr Biol 19: 1351-1355.

Brembs B, Heisenberg M. 2000. The operant and the classical in conditioned orientation of Drosophila melanogaster at the flight simulator. Learn Mem 7: 104-115.
Brembs B, Plendl W. 2008. Double dissociation of PKC and AC manipulations on operant and classical learning in Drosophila. Curr Biol 18: $1168-1171$.

Brembs B, Christiansen F, Pfluger HJ, Duch C. 2007. Flight initiation and maintenance deficits in flies with genetically altered biogenic amine levels. J Neurosci 27: 11122-11131.

Cheng Y, Endo K, Wu K, Rodan AR, Heberlein U, Davis RL. 2001. Drosophila fasciclinII is required for the formation of odor memories and for normal sensitivity to alcohol. Cell 105: 757-768.

Claridge-Chang A, Roorda RD, Vrontou E, Sjulson L, Li H, Hirsh J, Miesenbock G. 2009. Writing memories with light-addressable reinforcement circuitry. Cell 139: 405-415.

Connolly JB, Roberts IJ, Armstrong JD, Kaiser K, Forte M, Tully T, O'Kane CJ. 1996. Associative learning disrupted by impaired Gs signaling in Drosophila mushroom bodies. Science 274: 2104-2107.

Crittenden JR, Skoulakis EMC, Han K-A, Kalderon D, Davis RL. 1998. Tripartite mushroom body architecture revealed by antigenic markers. Learn Mem 5: 38-51.

Davis RL. 2005. Olfactory memory formation in Drosophila: From molecular to systems neuroscience. Annu Rev Neurosci 28: $275-302$.

de Belle JS, Heisenberg M. 1994. Associative odor learning in Drosophila abolished by chemical ablation of mushroom bodies. Science 263: 692-695.

Diegelmann S, Zars M, Zars T. 2006. Genetic dissociation of acquisition and memory strength in the heat-box spatial learning paradigm in Drosophila. Learn Mem 13: 72-83.

Dill M, Wolf R, Heisenberg M. 1993. Visual pattern recognition in Drosophila involves retinotopic matching. Nature 365: 751-753.

Drier EA, Tello MK, Cowan M, Wu P, Blace N, Sacktor TC, Yin JC. 2002. Memory enhancement and formation by atypical PKM activity in Drosophila melanogaster. Nat Neurosci 5: 316-324.

Dubnau J, Grady L, Kitamoto T, Tully T. 2001. Disruption of neurotransmission in Drosophila mushroom body blocks retrieval but not acquisition of memory. Nature 411: $476-480$.

Feany MB, Quinn WG. 1995. A neuropeptide gene defined by the Drosophila memory mutant amnesiac. Science 268: 869-873.

Ferris J, Ge H, Liu L, Roman G. 2006. G(o) signaling is required for Drosophila associative learning. Nat Neurosci 9: 1036-1040.

Friggi-Grelin F, Coulom H, Meller M, Gomez D, Hirsh J, Birman S. 2003. Targeted gene expression in Drosophila dopaminergic cells using regulatory sequences from tyrosine hydroxylase. J Neurobiol 54: $618-627$.

Gerber B, Tanimoto H, Heisenberg M. 2004. An engram found? Evaluating the evidence from fruit flies. Curr Opin Neurobiol 14: 737-744.

Gerber B, Stocker RF, Tanimura T, Thum AS. 2009. Smelling, tasting, learning: Drosophila as a study case. Results Probl Cell Differ 47: $139-185$.

Gervasi N, Tchénio P, Preat T. 2010. PKA dynamics in a Drosophila learning center: Coincidence detection by rutabaga adenylyl cyclase and spatial regulation by dunce phosphodiesterase. Neuron 64: 516-529.

Gioia A, Zars T. 2009. Thermotolerance and place memory in adult Drosophila are independent of natural variation at the foraging locus. J Comp Physiol A 195: 777-782.

Heisenberg M. 2003. Mushroom body memoir: From maps to models. Nat Rev Neurosci 4: 266-275.

Heisenberg M, Gerber B. 2008. Behavioral analysis of learning and memory in Drosophila. In Learning and memory: A comprehensive reference (ed. R Menzel and J Byrne), pp. 549-560. Elsevier, Oxford, UK.

Heisenberg M, Borst A, Wagner S, Byers D. 1985. Drosophila mushroom body mutants are deficient in olfactory learning. J Neurogenet 2: 1-30.

Heisenberg M, Wolf R, Brembs B. 2001. Flexibility in a single behavioral variable of Drosophila. Learn Mem 8: 1-10.

Ito K, Suzuki K, Estes P, Ramaswami M, Yamamoto D, Strausfeld NJ. 1998 The organization of extrinsic neurons and their implications in the functional roles of the mushroom bodies in Drosophila melanogaster Meigen. Learn Mem 5: 52-77.

Kaun KR, Hendel T, Gerber B, Sokolowski MB. 2007. Natural variation in Drosophila larval reward learning and memory due to a cGMP-dependent protein kinase. Learn Mem 14: 342-349.

Kawecki TJ, Mery F. 2006. Genetically idiosyncratic responses of Drosophila melanogaster populations to selection for improved learning ability. J Evol Biol 19: 1265-1274.

Keene AC, Waddell S. 2007. Drosophila olfactory memory: Single genes to complex neural circuits. Nat Rev Neurosci 8: 341-354.

Krashes MJ, Keene AC, Leung B, Armstrong JD, Waddell S. 2007. Sequential use of mushroom body neuron subsets during Drosophila odor memory processing. Neuron 53: 103-115.

Krashes MJ, Dasgupta S, Vreede A, White B, Armstrong JD, Waddell S. 2009. A neural circuit mechanism integrating motivational state with memory expression in Drosophila. Cell 139: 416-427. 
Laferriere H, Guarnieri DJ, Sitaraman D, Diegelmann S, Heberlein U, Zars T. 2008. Genetic dissociation of ethanol sensitivity and memory formation in Drosophila melanogaster. Genetics 178: 1895-1902.

Liu L, Wolf R, Ernst R, Heisenberg M. 1999. Context generalization in Drosophila visual learning requires the mushroom bodies. Nature 400: $753-756$.

Liu G, Seiler H, Wen A, Zars T, Ito K, Wolf R, Heisenberg M, Liu L. 2006. Distinct memory traces for two visual features in the Drosophila brain. Nature 439: 551-556.

Mao Z, Davis RL. 2009. Eight different types of dopaminergic neurons innervate the Drosophila mushroom body neuropil: Anatomical and physiological heterogeneity. Front Neural Circuits 3: 5. doi: 10.3389/ neuro.04.005.2009.

Mao Z, Roman G, Zong L, Davis RL. 2004. Pharmacogenetic rescue in time and space of the rutabaga memory impairment by using Gene-Switch. Proc Natl Acad Sci USA 101: 198-203.

McGuire SE, Le PT, Davis RL. 2001. The role of Drosophila mushroom body signaling in olfactory memory. Science 293: 1330-1333.

McGuire SE, Le PT, Osborn AJ, Matsumoto K, Davis RL. 2003. Spatiotemporal rescue of memory dysfunction in Drosophila. Science 302: $1765-1768$.

McGuire SE, Deshazer M, Davis RL. 2005. Thirty years of olfactory learning and memory research in Drosophila melanogaster. Prog Neurobiol 76: $328-347$.

Mery F, Kawecki TJ. 2002. Experimental evolution of learning ability in fruit flies. Proc Natl Acad Sci USA 99: 14274-14279.

Mery F, Belay AT, So AK, Sokolowski MB, Kawecki TJ. 2007. Natural polymorphism affecting learning and memory in Drosophila. Proc Natl Acad Sci USA 104: 13051-13055.

Moore MS, DeZazzo J, Luk AY, Tully T, Singh CM, Heberlein U. 1998. Ethanol intoxication in Drosophila: Genetic and pharmacological evidence for regulation by the cAMP signaling pathway. Cell 93: 997-1007.

Neuser K, Triphan T, Mronz M, Poeck B, Strauss R. 2008. Analysis of a spatial orientation memory in Drosophila. Nature 453: 1244-1247.

Osborne KA, Robichon A, Burgess E, Butland S, Shaw RA, Coulthard A, Pereira HS, Greenspan RJ, Sokolowski MB. 1997. Natural behavior polymorphism due to a cGMP-dependent protein kinase of Drosophila. Science 277: 834-836.

Pascual A, Preat T. 2001. Localization of long-term memory within the Drosophila mushroom body. Science 294: 1115-1117.

Pavlov IP. 1927. Conditioned reflexes. Oxford University Press, London, UK.

Putz G. 2002. Characterization of memories and ignorant (S6KII) mutants in operant conditioning in the heat-box. In Department of genetics and neurobiology, pp. 115. Julius Maximillians Universitaet Wuerzburg, Wuerzburg, Germany.

Putz G, Heisenberg M. 2002. Memories in Drosophila heat-box learning. Learn Mem 9: 349-359.

Putz G, Bertolucci F, Raabe T, Zars T, Heisenberg M. 2004. The S6KII (rsk) gene of Drosophila melanogaster differentially affects an operant and a classical learning task. J Neurosci 24: 9745-9751.

Scherer S, Stocker RF, Gerber B. 2003. Olfactory learning in individually assayed Drosophila larvae. Learn Mem 10: 217-225.

Schroll C, Riemensperger T, Bucher D, Ehmer J, Voller T, Erbguth K, Gerber B, Hendel T, Nagel G, Buchner E, et al. 2006. Light-induced activation of distinct modulatory neurons triggers appetitive or aversive learning in Drosophila larvae. Curr Biol 16: $1741-1747$.

Schwaerzel M, Heisenberg M, Zars T. 2002. Extinction antagonizes olfactory memory at the sub-cellular level. Neuron 35: 951-960.

Schwaerzel M, Monastirioti M, Scholz H, Friggi-Grelin F, Birman S, Heisenberg M. 2003. Dopamine and octopamine differentiate between aversive and appetitive olfactory memories in Drosophila. J Neurosci 23: 10495-10502.
Selcho M, Pauls D, Han KA, Stocker RF, Thum AS. 2009. The role of dopamine in Drosophila larval classical olfactory conditioning. PLoS ONE 4: e5897.

Sitaraman D, Zars T. 2010. Place memory formation in Drosophila is independent of proper octopamine signaling. J Comp Physiol [A] 196: 299-305.

Sitaraman D, Zars M, Laferriere H, Chen YC, Sable-Smith A, Kitamoto T, Rottinghaus GE, Zars T. 2008. Serotonin is necessary for place memory in Drosophila. Proc Natl Acad Sci USA 105: 5579-5584.

Skinner BF. 1950. Are theories of learning necessary? Psychol Rev 57: 193-216.

Tanaka NK, Tanimoto H, Ito K. 2008. Neuronal assemblies of the Drosophila mushroom body. J Comp Neurol 508: 711-755.

Tang S, Guo A. 2001. Choice behavior of Drosophila facing contradictory visual cues. Science 294: $1543-1547$.

Tang S, Wolf R, Xu S, Heisenberg M. 2004. Visual pattern recognition in Drosophila is invariant for retinal position. Science 305: 1020-1022.

Tanimoto H, Heisenberg M, Gerber B. 2004. Experimental psychology: Event timing turns punishment to reward. Nature 430: 983.

Tomchik SM, Davis RL. 2009. Dynamics of learning-related cAMP signaling and stimulus integration in the Drosophila olfactory pathway. Neuron 64: 510-521.

Tully T, Quinn WG. 1985. Classical conditioning and retention in normal and mutant Drosophila melanogaster. J Comp Physiol [A] 157: $263-277$.

Tully T, Preat T, Boynton SC, Del Vecchio M. 1994. Genetic dissection of consolidated memory in Drosophila. Cell 79: 35-47.

Waddell S, Armstrong JD, Kitamoto T, Kaiser K, Quinn WG. 2000. The amnesiac gene product is expressed in two neurons in the Drosophila brain that are critical for memory. Cell 103: 805-813.

Wang Z, Pan Y, Li W, Jiang H, Chatzimanolis L, Chang J, Gong Z, Liu L. 2008. Visual pattern memory requires foraging function in the central complex of Drosophila. Learn Mem 15: 133-142.

Wolf R, Wittig T, Liu L, Wustmann G, Eyding D, Heisenberg M. 1998. Drosophila mushroom bodies are dispensible for visual, tactile, and motor learning. Learn Mem 5: 166-178.

Wustmann G, Heisenberg M. 1997. Behavioral manipulation of retrieval in a spatial memory task for Drosophila melanogaster. Learn Mem 4: $328-336$

Wustmann G, Rein K, Wolf R, Heisenberg M. 1996. A new paradigm for operant conditioning of Drosophila melanogaster. J Comp Physiol [A] 179: 429-436.

Xia SZ, Liu L, Feng CH, Guo A. 1997. Memory consolidation in Drosophila operant visual learning. Learn Mem 4: 205-218.

Yarali A, Krischke M, Michels B, Saumweber T, Mueller MJ, Gerber B. 2009. Genetic distortion of the balance between punishment and relief learning in Drosophila. J Neurogenet 23: 235-247.

Zars T. 2000. Behavioral functions of the insect mushroom bodies. Curr Opin Neurobiol 10: 790-795.

Zars T. 2009. Spatial orientation in Drosophila. J Neurogenet 23: 104-110.

Zars T. 2010. Visualizing PKA activity in a learning center. Neuron 4: $442-444$.

Zars M, Zars T. 2006. High and low temperatures have unequal reinforcing properties in Drosophila spatial learning. J Comp Physiol [A] 192: 727-735.

Zars T, Fischer M, Schulz R, Heisenberg M. 2000a. Localization of a short-term memory in Drosophila. Science 288: 672-675.

Zars T, Wolf R, Davis R, Heisenberg M. 2000b. Tissue-specific expression of a type I adenylyl cyclase rescues the rutabaga mutant memory defect: In search of the engram. Learn Mem 7: 18-31.

Received November 19, 2009; accepted in revised form February 12, 2010. 


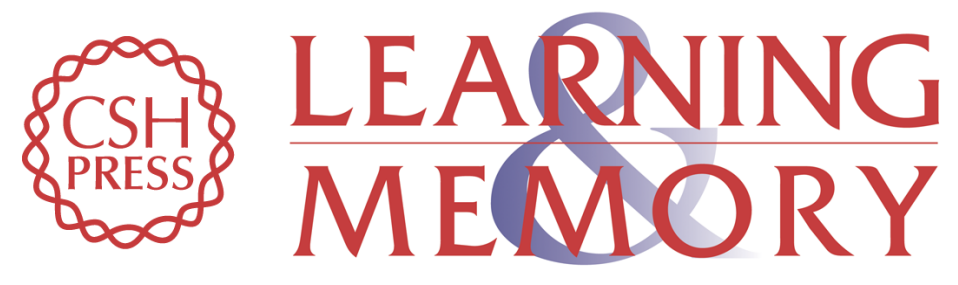

\section{Short-term memories in Drosophila are governed by general and specific genetic systems}

Troy Zars

Learn. Mem. 2010, 17:

Access the most recent version at doi:10.1101//m.1706110

References This article cites 77 articles, 30 of which can be accessed free at:

http://learnmem.cshlp.org/content/17/5/246.full.html\#ref-list-1

License

Email Alerting Receive free email alerts when new articles cite this article - sign up in the box at the Service top right corner of the article or click here. 